\title{
Social Trends - past, present, future
}

I am delighted to introduce this edition of Social Trends, the latest statistical picture of life in the UK compiled by the Office for National Statistics and colleagues across the Government Statistical Service. There have been marked social changes over the last 40 years, since Social Trends was first published in 1970. Changes in the pattern of our working lives - who is employed, where and how - have accompanied changes in household and family structure. There is greater material wealth, although there are still large variations in income and wealth, as well as in health and educational attainment.

To mark the 40th anniversary, this edition includes some description of long term trends in every chapter. The Social Trends team has also prepared an article drawing on past editions, and a time line, to show some of the ways in which the UK and the world are very different places now, compared with 40 years ago.

The statistical landscape was changed by the arrival of Social Trends. Historically it had been economic, production and labour market statistics that were predominantly used in political and public discussion and debate, with social statistics tending to be limited to tracking the size of the population. Social Trends was created in response to the growing need for economic progress to be measured, at least in part, in terms of social benefits. This need remains, as exemplified by the publication in 2009 of the Stiglitz-Sen-Fitoussi report recommending ways of measuring economic performance and social progress.

In an article in the first edition of Social Trends, Professor Claus Moser, then the director of the Central Statistical Office, suggested that Social Trends would be a success if it helped public understanding and discussion of social policy. The publication was indeed a success - it has attracted enormous publicity and featured on lists of Christmas reading recommended by a number of national papers. Social Trends has remained a flagship publication from the ONS for the whole of the Government Statistical Service. It is regularly welcomed as a 'must-read for anyone working in advertising, marketing or social policy' (The China Post) and even 'a sort of up-market Guinness Book of Records, recording the way we live now' (The Guardian).

While the mission of Social Trends is unchanged, the content has developed. New data have become available and areas of interest change. For example, chapters on the environment and on transport have been introduced. The lifestyles and social participation chapter has grown. A chapter specifically on our 'e-society' is being prepared for future editions.

Social Trends is itself evolving and this will be the last edition in book form. Social Trends and supporting data tables have been available from the ONS website for 10 years. From now on, Social Trends will be disseminated wholly as a web publication, with material being published throughout the year. This will provide more timely releases of statistics and commentary on changes in UK society.

I regularly refer to Social Trends, and with not a little pride as the editor for four editions that spanned the turn of the millennium. Looking back through the cuttings, I was amused to see one from that time headlined 'Women swap sewing needles for DIY'. Long may Social Trends continue to capture and present social trends of all kinds. Statistics matter. Social Trends helps deliver my vision: statistics, analysis and advice used in debate and decision-making.

Thank you to everyone involved in compiling Social Trends.

\section{Jil Matmuon}

Jil Matheson

National Statistician

June 2010 